\title{
OBJETIVIDADE E AVENTURA:MACHADO DE ASSIS A PARTIR DO CASMURRO SÍLVIO ROMERO
}

\author{
Maurício Maia Aguiar \\ Universidade Federal de Campina Grande \\ Campina Grande, Paraíba, Brasil
}

\begin{abstract}
Resumo: Sílvio Romero, o leitor mais severo da obra de Machado de Assis, tornou-se conhecido no pensamento social brasileiro devido ao seu maior equívoco: decretar a irrelevância da obra de Machado. A investigação desse equívoco nos remete diretamente a uma compreensão dos pressupostos teóricos deste importante historiador da literatura, sua aproximação ao positivismo e naturalismo e às diretrizes políticas, estéticas e doutrinárias desenvolvidas pela "Geração de 1870". Deste modo, a crítica literária de Sílvio Romero sobre a obra de Machado de Assis nos permite tanto lançar luz às redes de sociabilidade artística/intelectual no Brasil do final do século XIX, como ainda descrever os modelos de intelectual e artista considerados por ele adequados ou não diante do processo de formação racial brasileira.
\end{abstract}

Palavras-chave: Machado de Assis; Sílvio Romero; crítica literária.

\section{Objectivity and adventure: Machado de Assis's through the casmurro Sílvio Romero}

\begin{abstract}
Silvio Romero, the most severe reader of Machado de Assis, became known in the Brazilian social thought for his biggest mistake: to decry this author's work for its irrelevance. Research on this mistake reveal the influence of positivism and naturalism on this important literary historian's theoretical assumptions and also the political, aesthetic and doctrinal guidelines developed by the generation of 1870. Indeed, Silvio Romero's literary reviews on Machado de Assis provide an understanding of artistic/intellectual sociability in Brazil at the end of the 19th Century and describe the intellectual and artistic roles that he considered appropriate for the Brazilian race-building process.
\end{abstract}

Keywords: Machado de Assis; Sílvio Romero; literary criticism.

\section{Introdução}

Abordo neste artigo dois aspectos pontuais nas considerações críticas de Sílvio Romero sobre Machado de Assis, portanto sem pretensões de sistematizar seu pensamento e nem fornecer uma narrativa biográfica do crítico literário. Os esforços em ambas as direções já foram realizados com sucesso por Sylvio Rabello e Antonio 
Candido, ${ }^{1}$ cujas obras se tornaram referência para o estudo do crítico sergipano. Minha intenção se limita a explorar dois pontos bem específicos a partir do controverso livro de Sílvio Romero sobre Machado de Assis. ${ }^{2}$

O primeiro aspecto a ser observado é o perfil de Machado criado por Sílvio Romero, em que o escritor fluminense é apresentado como uma anomalia em relação ao meio nacional. Para ser possível compreender mais detidamente esse perfil, é importante identificar os referenciais teóricos de Sílvio Romero e como ele transforma a arte em objeto preferencial para analisar a nação. $O$ segundo aspecto se refere ao modelo de intelectual desenvolvido com a geração de 1870 e que tem em Sílvio Romero uma expressão mais intensa. ${ }^{3}$ Dessa forma, o livro de Sílvio Romero funciona também como um espelho, pois revela alguns de seus anseios e modelos à medida que traça o retrato de Machado de Assis.

Esses dois pontos a serem tratados ao longo do artigo estão, na verdade, articulados. Parto do pressuposto de que tanto os parâmetros utilizados na construção do perfil de Machado de Assis por Sílvio Romero como ainda o modelo de intelectual defendido pelo crítico literário nos fornecem uma "forma de vida", ${ }^{4}$ uma possibilidade de encontrar homologias entre determinados traços biográficos do autor e suas premissas científicas e estéticas. Este tipo de abordagem é uma oportunidade de escapar tanto da dicotomia entre texto e contexto, como das consequências indesejáveis de reduzir a obra e a vida de Sílvio Romero à condição de testemunha histórica de determinado momento nacional ou, ao contrário, considerar suas discussões apenas como uma etapa da evolução das ideias científicas.

Nesse sentido, o conceito de "forma de vida" nos ajuda a perceber como, ao criar um perfil de Machado de Assis, Sílvio Romero revelou seus próprios parâmetros de julgamento crítico e o modelo de intelectual e artista nacional que julgava adequado. O que faz do seu retrato de Machado uma oportunidade para defesa, pretensamente científica, de um princípio que não se restringe às questões teóricas e metodológicas, pois tem entre seus objetivos nos apresentar um quadro de referências para a conduta

\footnotetext{
${ }^{1}$ RABELLO, Itinerário de Sylvio Romero, 1944; CANDIDO, O método crítico de Sílvio Romero, 1988.

${ }^{2}$ ROMERO, Machado de Assis: Estudo comparativo de literatura brasileira, 1992.

${ }^{3}$ AGUIAR, Retratos de Machado de Assis: sabedoria, genialidade e melancolia na crítica literária fin de siècle, p. 78. Acesso em: 15 de dez. 2013.

${ }^{4}$ LUKÁCS, On the nature and form of the essay, p. 8.
} 
ideal do artista e do intelectual brasileiro, ao qual ele mesmo se baseia para justificar seu pensamento e suas ações.

Esse quadro de referências nos revela formas de percepção inerentes ao universo intelectual e artístico do Brasil, principalmente do Rio de Janeiro, do século XIX. Desse modo, não se questionará a veracidade do perfil de Machado de Assis criado por Sílvio Romero, pois apenas darei ênfase às categorias que mobilizou para o desenho de seu retrato. Assim, seus pressupostos teóricos e estéticos serão tratados como categorias nativas, formas de construção do sentido da realidade. ${ }^{5}$

Há um conjunto de categorias mobilizadas como "raça", "meio geográfico", "espírito representativo", entre outras, que supõem a existência de uma perfeita simbiose entre literatura, em um sentido amplo, e o temperamento nacional, pois ambos seriam a manifestação do "determinismo psicofisiológico" ${ }^{6}$ com que Sílvio enxergava a sociedade. $\mathrm{O}$ estudo da literatura proporcionaria um vislumbre da própria nação, pois o literato ou intelectual sempre reproduziria certos traços do comportamento mais geral da sociedade. O gênio artístico nacional, que para Sílvio seria expressão máxima de uma índole coletiva, o espírito da sociedade, ${ }^{7}$ só poderia ser resultado, principalmente, do processo de formação racial do Brasil. Essa contribuição de Sílvio Romero é, inclusive, ressaltada por intelectuais da geração modernista, e Antonio Candido e Sylvio Rabello destacam a originalidade dessa interpretação como a fonte dos estudos de Gilberto Freyre nos anos $30 .^{8}$ Desse modo, a mestiçagem - considerada por Sílvio Romero também como um processo de modelagem moral constitutivo da sociedade - tenderia a criar um traço geral da índole nacional. E tal processo ainda estaria em estágio inicial no Brasil; a formação da raça não teria ainda atingido maior grau de "maturidade" e, de certo modo, é uma das responsáveis pela frágil tradição nacional.

\footnotetext{
${ }^{5}$ WEBER, A objetividade do conhecimento na ciência social e na ciência política, p. 152-153.

${ }^{6}$ CANDIDO, cit., p.104.

7 Esta discussão foi feita por Taine, importante referência teórica de Sílvio Romero, para quem este espírito, esta "temperatura moral", é delineada pelo meio e pela situação, pela combinação de um conjunto de fatores históricos que produzem esse espírito representativo da sociedade, expresso com mais força pelas variadas formas de arte. TAINE, Da natureza e produção da obra de arte, p. 90 e 93.

${ }^{8}$ CANDIDO, cit., p.60; RABELLO, cit., p. 87. Entretanto, ao contrário da acepção mais complexa de Gilberto Freyre, muito mais articulada com os processos históricos da formação nacional e o papel das microssociedades dos engenhos, Sílvio se atém mais ao processo de formação da "raça" brasileira.
} 
A tentativa de vincular tradição e traços raciais era bastante recorrente na linguagem da "Geração de 1870", inclusive com conclusões similares acerca da fragilidade da tradição nacional. ${ }^{9}$ Para Sílvio, essa tradição tinha sido apenas esboçada durante o período colonial e corria o risco de não atingir a maturidade, pois o crítico enxergava o processo histórico de praticamente todo o século XIX como um desvio desta tradição incipiente. Para ele, as modernizações do segundo reinado e a implantação da sociedade de corte ameaçavam a frágil tradição nacional ao imporem modelos de convivência social e de diretrizes de desenvolvimento exógenos aos trópicos. A incompletude desse processo se evidenciaria, principalmente, na insegurança de literatos e artistas em evidenciar essa tradição, ou pelo menos caminhar na direção de sua afirmação. Essa teoria lhe forneceu os contornos de seu retrato de Machado de Assis.

\section{O temeroso mestiço}

Baseado em leituras principalmente de Taine, Sílvio tentou desqualificar a definição usual entre os críticos da época a respeito do humour e pessimismo em Machado. ${ }^{10}$ Segundo o crítico, o temperamento artístico no Brasil seria impulsionado por certas características de nossa formação histórica, biológica e do meio físico, e tais estéticas e filosofias, como o humour, não seriam possíveis ao artista nacional por exigirem traços de temperamento incompatíveis com a índole, já em processo de formação, do brasileiro. Esses estilos literários seriam fenômenos recorrentes nos temperamentos nórdicos que, segundo o trecho de Taine citado por Sílvio, teriam condições ideais para o surgimento de determinadas individualidades mais afeitas às

\footnotetext{
${ }^{9}$ Além de Sílvio Romero, a quem esta afirmação sobre a ausência de tradição no país é recorrente como será demonstrado ao longo desse artigo, também José Veríssimo faz afirmações desse tipo. VERÍSSIMO, A literatura brazileira: Sua formação e destino, p. 1. Apesar de não ser um remanescente da Escola de Recife, José Veríssimo também estava sob a influência do movimento intelectual desencadeado em outras províncias. BARBOSA, A tradição do impasse: linguagem da crítica e crítica da linguagem em José Veríssimo, p. 77.

${ }^{10}$ Muitos críticos literários contemporâneos a Machado chamaram atenção para o humour e pessimismo em Machado, e o mais importante é, sem dúvida, Alcides Maya que dedicou um livro ao assunto em 1912, já após a morte de Machado. MAYA, Machado de Assis: algumas notas sobre o humour, 2007. A publicação desse livro se deu devido à motivação gerada por recomendações de intelectuais que acompanharam este tema tratado anteriormente por Alcides Maya em pequenas resenhas literárias, como a publicada em O Paiz, Rio de Janeiro, 8 de outubro de 1904. GUIMARÃES, Os leitores de Machado de Assis: o romance machadiano e o público de literatura no século 19, p. 430-433.
} 
[...] reviravoltas inesperadas do instinto físico, tão diverso das raças latinas e clássicas, raças de oradores e artistas, que só escrevem pensando no público, só apreciam as ideias concatenadas, que só se deliciam pelo espetáculo das formas harmoniosas, cuja imaginação é regulada e cuja própria volúpia parece natural. ${ }^{11}$

Logo após citar Taine, Sílvio ironiza a classificação de Machado a partir do humour:

Ainda mais uma vez pergunto: onde acha-se tudo isto em nosso Machado de Assis, tão lógico, tão lúcido, tão sossegado, tão tranquilo? Não sei bem ao certo se ele é um germano em qualquer grau $\left[\ldots . .{ }^{12}\right.$

Os brasileiros, principalmente os mestiços, seriam peculiares, tendendo a outros padrões de comportamento, como podemos ver neste trecho seguinte, em que Ś́lvio desqualifica a classificação de Machado como pessimista:

Nós brasileiros somos faladores, maldizentes, desrespeitadores das conveniências, assaz irrequietos, até onde nos deixa ir nossa ingênita apatia de meridionais, mas não somos pessimistas, nem nos agrada o terrível desencanto de tudo sob as formas desesperadoras dos nirwanistas a Buda ou a Schopenhauer. ${ }^{13}$

Essas três citações evidenciam os parâmetros de julgamento sobre a relação entre raça e estilo literário e ainda apontam para uma suposta incongruência entre o estilo adotado por Machado e a manifestação natural de sua índole. Provavelmente, como salientado na citação seguinte, Machado nem mesmo seria provido de um temperamento apropriado para a arte. A descrição de Sílvio Romero a respeito da "timidez" e "medo", a qual repete ao longo de todo o livro, atrapalharia a escrita de Machado, comprometendo a clareza. Novamente Sílvio recorre à concepção de artificialidade do estilo de Machado, agora em outra direção, como podemos ver logo a seguir:

\footnotetext{
${ }^{11}$ Sílvio não menciona a referência bibliográfica do livro de Taine. SÍLVIO, cit., p. 166.

${ }^{12}$ Idem, p. 166.

${ }^{13}$ Idem, p. 256.
} 
$\mathrm{O}$ estilo de Machado de Assis, sem ter grande originalidade, sem ser notado por um forte cunho pessoal, é a fotografia exata do seu espírito, de sua índole psicológica indecisa. Correto e maneiroso, não é vivaz, nem rútulo, nem grandioso, nem eloquente. É plácido e igual, uniforme e compassado. Sente-se que o autor não dispõe profusamente, espontaneamente do vocabulário e da frase. Vê-se que ele apalpa e tropeça, que sofre de uma perturbação qualquer nos órgãos da palavra. Sente-se o esforço, a luta. "Ele gagueja no estilo, na palavra escrita, como fazem outros na palavra falada", disse-me uma vez não sei que desabusado num momento de expansão, sem reparar talvez que dava-me destarte uma verdadeira e admirável notação crítica. $^{14}$

Se antes a artificialidade estava associada apenas à ideia de imitação de estilos exógenos ao temperamento nacional em formação, agora Sílvio destaca a artificialidade como esforço, como a expressão antinatural, que exige muito do artista por não provir de um sentimento espontâneo e, ainda, devido a um tipo de labor somente necessário àqueles que não são dotados da personalidade forte exigida pela arte.

Sílvio, portanto, deslegitima o estilo adotado por Machado e ainda o seu comportamento em sociedade, tanto pela dessemelhança em relação à sua descrição do brasileiro, como também por não possuir os "dotes" adequados. O seu caráter "tão lúcido, tão sossegado" contrasta com os brasileiros, "faladores", "irrequietos" e "desrespeitadores das conveniências" e ainda dá mostras de fraqueza de espírito. Essa "anomalia" de Machado, perseguida ao longo de todo livro, talvez fique mais explícita neste trecho que se segue:

Machado de Assis é, disse eu, um representante do espírito brasileiro, mas num momento mórbido, indeciso, anuviado, e por um modo incompleto, indireto, e como que a medo. [...] Não possui ainda (a nação brasileira) ideais conscientes a realizar, nem um corpo de tradições e feitos históricos que constituam uma espécie de modelo, de paradigma para ações futuras. ${ }^{15}$

Assim, Machado representava um momento de incerteza derivada do processo de miscigenação e formação histórica da sociedade, em que o caráter dúbio do

\footnotetext{
${ }^{14}$ Idem, p. 122.

${ }^{15}$ Idem, p. 153(Grifo meu).
} 
miscigenado $^{16}$ se manifestava em sua característica mais negativa. Nessa ausência de parâmetros tradicionais, como também de uma índole mais definida e estabelecida, Machado teria optado pela imitação de estilos inautênticos em detrimento da tendência natural do temperamento nacional como descrita pelo crítico.

Para Sílvio, a tendência do comportamento do brasileiro é aquela citada anteriormente, marcada pela inquietude e expansividade, e Machado, nesse sentido, ao ter desenvolvido um comportamento mais formal e "sossegado", parece ter recaído nas incertezas geradas pelo momento histórico. Esse aspecto só pode ser compreendido a partir da crítica que a Geração de 1870 fez principalmente ao romantismo e à Corte. Para Sílvio, a nação incipiente e sem tradição consolidada só volta a ter a chance de encontrar seus rumos a partir do marco histórico que atribuiu à própria Escola de Recife. Seus membros, principalmente Tobias Barreto, pretendiam identificar as tendências mais "positivas" da sociedade, o que passava evidentemente pelo desenvolvimento de formas "objetivas" de apreensão da realidade nacional, seja pela crítica ou pela literatura.

$\mathrm{O}$ "medo" de Machado diante o momento e a sua suposta postura titubeante se revelariam com o declínio do romantismo, pois Machado teria tomado, instintivamente, uma decisão pouco corajosa ao apelar para estéticas exógenas, em vez de enveredar por estilo literário comprometido por identificar a realidade nacional a partir de estudo mais sistemático e objetivo como pretendido pelas escolas naturalistas. Nesse equívoco, segundo Ś́lvio Romero, se revela tanto a sua fraqueza de caráter como sua recusa por representar a realidade nacional. A sua escolha pelo humorismo e pessimismo já revelariam muito dessa má decisão, segundo Sílvio, por assumir posturas descrentes e passivas diante a vida, que tendem a rejeitar todos os projetos, toda a luta pela construção de um espírito nacional mais forte que provesse de novo relevo as potencialidades da miscigenação.

O despropósito dessa má escolha estética se evidenciaria, ainda, na sua própria trajetória biográfica, como é possível identificar na citação seguinte:

\footnotetext{
${ }^{16}$ Essa caracterização do miscigenado a partir dessa plasticidade de acomodação que Sílvio utiliza para retratar Machado de Assis é muito similar ao tipo de tratamento realizado por Gilberto Freyre para analisar a ascensão social do mulato ao longo do século XIX. FREYRE, Sobrados e mucambos: decadência do patriciado rural e desenvolvimento do urbano, p. 600-659.
} 
Não sendo portador de pergaminho, que lhe abrisse a senda de qualquer profissão liberal, como a medicina, a advocacia, a engenharia ou qualquer outra ao jeito da magistratura, da diplomacia, do alto magistério, o nosso romancista atirou-se ao funcionalismo público de ordem administrativa, a princípio no Diário Oficial e mais tarde na Secretaria da Agricultura e Obras públicas, onde é o chefe de uma das diretorias.

Vida plácida, metódica, sem nada que jamais denunciasse qualquer desvio de boemia; mediania risonha, enaltecida pela nobreza de sua senhora, inteligente dama portuguesa, irmã do poeta Faustino Xavier de Novaes $[. ..]{ }^{17}$

A feição de tranquilidade e serenidade, anteriormente associada ao estilo literário de Machado, aqui se estende à sua conduta social. É como se Sílvio fizesse questão de destacar o temor pelo risco, como se na ausência de vigor intelectual e moral que lhe garantisse projeção no cenário público da Corte, Machado tivesse preferido "atirar-se ao funcionalismo público", devotar suas energias a uma ocupação mediana que lhe garantisse o sustento. $\mathrm{O}$ traço de "mediania risonha" reforça ainda mais essa pretensão de Sílvio Romero em indicar a trajetória de ascensão do escritor fluminense, como se fosse um indivíduo de capacidades medíocres cujo maior esforço seria o de agradar, conquistar a simpatia e dissimular as pretensões mais pragmáticas pela própria sobrevivência. Por último, há uma menção deliberada ao casamento de Machado com Carolina Xavier, que enaltece sua "mediania risonha", elevando-o a um status que não atingiria por si mesmo.

Nota-se que o mesmo esforço literário, representado pela imitação de estilos "exógenos" à própria natureza, é também direcionado, segundo Sílvio, para a ascensão social. E esta tentativa de unir literatura e trajetória social fica nítida na sua afirmação de que o "[...] humour de Machado de Assis é um pacato diretor de secretaria de Estado, e o horrível de seus livros é uma espécie de burguês prazenteiro, condecorado com a comenda da rosa". ${ }^{18}$ A menção ao "burguês prazenteiro" ressalta sua intenção em destacar a atitude de acomodação de Machado em face da profissão, devido a uma mal disfarçada crítica à mediania do funcionalismo público, principalmente quando associada à monarquia - como a menção à "comenda da rosa" não deixa dúvidas. Como se o "pacato diretor de secretaria de Estado" se omitisse em relação a qualquer iniciativa

\footnotetext{
${ }^{17}$ Idem, p. 60-61.

${ }^{18}$ Idem, p. 162.
} 
de originalidade, resignado às contingências que lhes são impostas e sem provas de vigor de personalidade.

\section{Ciência, literatura e evolucionismo}

O perfil estético e moral de Machado de Assis desenhado por Sílvio Romero revela a ambiguidade do seu pensamento. Ao mesmo tempo em que critica Machado pela sua imitação e rejeição da "verdadeira realidade brasileira", parece ter desdém ainda maior pela placidez de Machado diante das causas públicas. Essa ambiguidade se manifesta na tentativa de aproximar o positivismo e o naturalismo, ${ }^{19}$ ao defender o olhar objetivo e distanciado em relação aos determinismos da ação social e, mesmo assim, esperar um imperativo de força do artista, uma capacidade para transformar e influenciar a sociedade. Sua crítica a Machado ressalta essas duas direções, mas antes de avaliarmos as consequências dessa ambiguidade, é interessante reforçar o tom da defesa de Sílvio Romero pelo comprometimento público e social da arte, como podemos identificar logo a seguir:

\footnotetext{
Não importa isto uma aprovação a certos absenteísmos muito do gosto dos ânimos fracos, que entendem de salvaguardar a própria pureza, fugindo sistematicamente das tentações. É proceder que nunca aplaudiremos. A virtude prova-se no meio da luta. A sociedade não é um convento de monjas. Que grande mérito advém em não se cobrir do pó a quem não sai à liça do combate e deixa-se tranquilamente ficar em doce e sossegado aposento? Devemos todos, homens de letras ou não, interessar-nos pelas pugnas e pelas dores da pátria. ${ }^{20}$
}

Ainda que a obrigação de todos, homens de letras ou não, seja se interessar pelas "pugnas" e "dores da pátria", a atuação dos homens de letras parece ser um pouco distinta, pois se viabiliza, principalmente, através de sua obra. Essa implicação nacionalista na obra obriga a atividade literária a medir-se constantemente por um senso de responsabilidade pública. Impõe ao intelectual e artista a exigência de enxergar sua produção como uma forma especial de atuação política. Para Sílvio, o modelo exemplar seria Tobias Barreto - a quem Sílvio dá posição de destaque em relação a Machado, em

\footnotetext{
${ }^{19}$ CANDIDO, cit., p. 87.

${ }^{20}$ ROMERO, cit., p. 31.
} 
todas as áreas possíveis - e ainda Gonçalves Dias, cuja "mestiçagem" não teria se manifestado em sua feição negativa de insegurança, desejo de ascensão e medo.

Não cesso de combater ideias que julgo prejudiciais ao progresso e à unidade do povo brasileiro. Em um país como o nosso, ainda novo, sem tradições bem formadas, sem coesão social bem compacta, nunca é demais insistir sobre o seu caráter popular e histórico. Ainda mais é isto indispensável, tratando-se de um poeta como Gonçalves Dias, um genuíno brasileiro, um mestiço físico e moral, que será por muitos séculos uma das mais autênticas manifestações da alma deste povo. ${ }^{21}$

Com essas duas citações é possível identificar, em linhas gerais, o modelo intelectual e artístico defendido por Sílvio Romero. De um lado é imperativo o engajamento na luta e dar provas do próprio valor e distinção e, de outro lado, o intelectual e artista deve representar, de forma condensada, as mais "autênticas manifestações da alma" do seu povo. Esta dupla exigência revela a contradição entre a ideia de distinção e seu forte viés aristocrático e a necessidade de representação do "caráter popular", que converte a imaginação artística em objetividade ${ }^{22}$ e síntese da sociedade. O próprio autor formulou assim, como uma lei, a relação entre intelectual e sociedade:

Cada escritor é um centro de força, além de uma resultante; como centro de força, age como causa e fator de diferenciação e progresso; como resultante, é um efeito de um meio dado, de um grupo social e deve refletir as qualidades do agregado a que pertence. ${ }^{23}$

Com isso percebe-se que Sílvio não estava cego a essa aparente contradição entre ser ao mesmo tempo "centro de força" e "resultante" dos processos sociais, e é necessário investigar mais a fundo esse modelo de intelectual e artista que visava desenvolver.

A contradição entre o intelectual que é fruto do seu meio e ao mesmo tempo o altera em direção ao "progresso" se resolve teoricamente a partir de certo tipo de

${ }^{21}$ ROMERO, Poesia - segunda fase do romantismo, p. 64.

${ }^{22}$ A esse respeito Sylvio Rabello afirmou que Sílvio Romero era um espírito de curta imaginação, um "espírito geométrico" mais afeito às abstrações de sistemas filosóficos do que capaz de aproveitar a imaginação em qualquer grau, seja para auxílio da observação da realidade, seja como poeta, tendo em vista que defendia a objetividade também como parâmetro artístico. RABELLO, cit., p. 94.

${ }^{23}$ ROMERO, Machado de Assis: Estudo comparativo de literatura brasileira, p. 79. 
evolucionismo muito usual na segunda metade do século XIX. O próprio Sílvio Romero, ao conceber a sociedade como uma luta incessante, nos fornece algumas pistas. Mas talvez consigamos dar mais densidade à explicação através de um estudo de Simmel que trata especificamente de como o impacto das transformações da vida moderna se manifestou em um dos mais importantes intelectuais do século XIX: Nietzsche. Em um primeiro instante, Simmel trata de uma característica da atividade filosófica, considerada a partir da particularidade da "vida interior" de todo aquele que a ela se dedica, como pode ser percebido na passagem seguinte:

[...] para a maioria dos homens, a vida interna, o movimento da alma, se expressa de modo suficiente na elaboração espiritual de um pedaço ou de um aspecto do mundo, mas a vida interior de um filósofo, para saciar-se, precisa produzir uma imagem de toda a existência. Seu temperamento só se satisfaz ao compreender a totalidade fundamental do Ser, a partir da qual partem todas as diversidades. ${ }^{24}$

A vida interior do filósofo, que poderíamos, sem prejuízo da definição, estender a certo perfil de intelectual do século XIX, é descrita por essa propensão à totalidade, de somente se satisfazer com uma imagem de si próprio concatenada a uma dimensão mais abrangente da vida social, constituído por uma cosmologia que coordena símbolos e significados da vida, em uma espécie de sistema. O interessante dessa definição do intelectual é ser possível avaliá-la mediante o próprio contexto da vida moderna, período histórico definido por Simmel, neste estudo específico, através do impacto sofrido pelas sociedades ocidentais devido ao declínio do cristianismo e a supressão de sua própria totalidade cosmológica. ${ }^{25}$ A ausência de Deus teria provocado uma espécie de ansiedade intelectual, calcada na necessidade de produzir uma imagem abrangente da vida. ${ }^{26}$ Dessa maneira, parte da vocação intelectual moderna é prover essa

\footnotetext{
${ }^{24}$ SIMMEL, Schopenhauer e Nietzsche, p. 30-31

${ }^{25}$ Idem, p. 15. Weber se apoia na mesma concepção ao definir a modernidade a partir da ideia do ressurgimento do "politeísmo" e ressalta ainda que a busca por um sentido amplo da vida significou uma retomada estranha da pretensão cristã, feita curiosamente por alguns intelectuais e artistas modernos, devido suas dificuldades em lidar com essa maior amplitude de sentidos. WEBER, A ciência como vocação, p. 50-51.

26 "Esse anseio é a herança que o cristianismo deixou: a necessidade de algo definitivo nos movimentos da vida, necessidade que permanece existindo como um impulso vazio a um fim tornado inalcançável." SIMMEL, cit., p.15.
} 
versão mais previsível e estável do mundo, cujo "funcionamento" pode ser esclarecido, tornando possível até mesmo delinear certa tendência de transformação.

Esse conflito permanente da condição intelectual moderna, de deparar-se continuamente com um mundo a ser construído com novos significados, tem um conjunto de consequências muito diversas do ponto de vista da modelagem de sua subjetividade intelectual. É nesse contexto que Simmel apresenta uma discussão que vincula determinados modelos de subjetividade intelectual com a própria imagem de Deus. Se, por um lado, a ansiedade moderna tem o aspecto negativo de lançar o intelectual em um vazio a ser preenchido, por outro ela proporciona a possibilidade de elaboração da subjetividade como substituto de Deus, a formulação da ideia de "gênio" como uma espécie de Deus em miniatura. ${ }^{27}$

Curiosamente, essa concepção de genialidade tem um desdobramento peculiar para a interpretação que Simmel faz a respeito de Nietzsche. Ao contrário do que possa imaginar, a genialidade descrita como um Deus em miniatura não significa o desenvolvimento de uma imagem extremamente particular do mundo, como se o intelectual o desenhasse apenas a partir de suas próprias referências. Especificamente para Nietzsche, a sua visão de mundo, apesar de partir dessa ansiedade em substituir Deus por outra referência totalizante que abarque um sentido universal para o humano, somente é possível com a objetividade.

No plano puramente espiritual é unânime considerar-se a objetividade como sinônimo de nobreza. O espírito diferenciado trata objetivamente a opinião contrária, não se deixa arrebatar por uma paixão subjetiva, só usa argumentos objetivos. Sua distinção aparece como uma conduta formal, na qual coincidem de maneira característica uma personalidade decidida e uma objetividade também decidida. ${ }^{28}$

A objetividade, nesse sentido, não significa somente a supressão de uma perspectiva particular ou do próprio indivíduo. Ela pode se tornar instrumento para a modelagem do indivíduo distinguido, o gênio que recriará a cosmologia ocidental em bases diversas daquela desenvolvida pelo cristianismo. E aqui se trata de compreender o

\footnotetext{
${ }^{27}$ Tomo de empréstimo o termo cunhado por Ricardo Benzaquen de Araújo em seu estudo sobre Gilberto Freyre. ARAÚJO, Deuses em miniatura: Notas sobre genialidade e melancolia em Gilberto Freyre, p. 97104.

${ }^{28}$ SIMMEL, cit.,p. 206-207.
} 
lugar do entendimento na cultura intelectual moderna, pois para além da compreensão da objetividade apenas como uma espécie de frieza e distanciamento, ela se torna um ponto de partida para descrever certo tipo de genialidade. Um gênio que tem por principal instrumento a própria objetividade e que se converterá em modelo de subjetividade para parte de artistas e intelectuais do século XIX.

É necessário acrescentar que não é arbitrário o uso da palavra "distinção" no trecho acima, pois ela se remete a um dos traços da cultura aristocrática que se recusa a qualquer forma de nivelamento, no qual o sentimento de igualdade, tanto aquele proporcionado por espaços de sociabilidade como pela massificação das cidades modernas, é tido como empecilho ao desenvolvimento dessa forma de gênio que, na teoria nietzschiana, congrega em si todo potencial evolutivo do espírito humano, como podemos verificar nessa passagem onde Simmel analisa o caráter peculiar do evolucionismo nietzschiano:

Imaginar que a humanidade possa marchar adiante no mesmo passo é um pensamento utópico e sem sentido. A força dos débeis está na debilidade dos fortes. A evolução só pode se realizar se os indivíduos estiverem diferenciados conforme seus distintos valores, de modo que um ou poucos possam os que os demais não podem. ${ }^{29}$

Estamos diante de uma forma pouco usual de compreender o pensamento filosófico amparado na objetividade e em certas tendências racionalistas da própria ciência durante o século XIX. Contudo, o potencial desta análise evidencia-se proveitosa para compreendermos a reconfiguração específica do modelo de intelectual e artista que surge neste processo. Pois ao longo do século XIX se delineia outro perfil, insubordinado a qualquer nivelamento e que se sente como um deus em miniatura, capaz de recriar o mundo a partir de sua capacidade superior em mobilizar a objetividade. Um modelo novo de subjetividade artística/intelectual, que fatalmente passou a prescrever exigências muito distintas à produção literária. Dessa maneira, a Geração de 1870, imbuída deste espírito racionalista e lutando contra o cristianismo, contra a imaginação romântica e, principalmente, com uma busca por autenticidade nacional inconciliável com o padrão cortesão do regime monárquico, possui grandes afinidades com este novo modelo de intelectual descrito por Simmel em sua análise

\footnotetext{
${ }^{29}$ Idem, p. 189.
} 
sobre Nietzsche. As possibilidades de correlação entre o modelo intelectual representado por Sílvio Romero e este expresso por Simmel para caracterizar o filósofo do século XIX serão objetos das conclusões a seguir.

\section{Algumas considerações finais}

A apresentação do modelo intelectual buscado por Nietzsche, pelo menos a partir da interpretação de Simmel, nos ajuda a pensar, de uma maneira geral, certas tendências da forma de vida de intelectuais posteriores ao declínio do cristianismo ao longo do século XIX e sua crescente substituição pelo "conhecimento objetivo". Sílvio Romero demonstra a mesma ansiedade por sistematizar a realidade a sua volta, que, em seu caso, parecia se reduzir à narrativa nacionalista do Brasil, à busca pelo caráter "popular e histórico", pelas "autênticas manifestações da alma" deste povo. Nesse sentido, a narrativa nacionalista se converteu em uma história linear que possui seus próprios mitos originários, a miscigenação, e até mesmo um destino, que é a formação de uma raça peculiar baseada na expansividade do espírito e também na criação de instituições mais representativas da vontade popular.

A construção mítica do destino brasileiro, da perfeita identificação de matrizes da formação de seu temperamento, passa pelo papel do intelectual e do artista, que, de forma "autêntica", portanto com espontaneidade, dá vazão a sentimentos mais em sintonia com as feições da sociedade. Não se trata, portanto, de modelos de perfeição simplesmente, pois, nesse caso específico, o homem distinguido não é aquele que supera seu entorno, e sim o que consegue representar, de maneira condensada, todas as potencialidades de sua raça. Nesse sentido, não há propriamente uma questão moral em jogo, e sim saber integrar qualidades e defeitos de maneira positiva, pois ao gênio, ainda que da raça, a sua superioridade lhe conferiria licença para pecar. ${ }^{30} \mathrm{Com}$ isso, talvez seja mais fácil compreender a intempestividade de Sílvio não apenas como uma característica de sua personalidade, a ser ressaltada como uma história particular do seu comportamento social registrado nas constantes polêmicas em que se envolvia. Ao justificar sua tendência ao embate, ele próprio defende a rebeldia, quando, no prefácio ao seu livro de poemas, menciona as críticas severas que levou, respondendo que o

\footnotetext{
${ }^{30}$ ARAÚJO, cit.,p. 102
} 
"crime do author (ele mesmo) há sido faltar com o respeito a umas ideias franzinas que lhe quizeram sempre impor como grandezas! Foi e será sempre rebelde ao culto dos numes litterarios de nossa terra [...]." ${ }^{31}$ Portanto, sem pudor algum, Sílvio defende a ausência de "respeito", aplicado aí em um sentido de liberdade e autonomia intelectuais, a tudo que lhe parecesse fraqueza e, por isso mesmo, precisasse ser superada com argumentos considerados por ele mais robustos. Apenas esse propósito, por si só, justificaria sua ironia nada sutil, como recurso para dotar suas análises com maior efeito retórico. Toda sua linguagem é uma retórica de luta, de desafio, na certeza de que a melhor ideia surgiria durante os duelos literários e, com isso, o homem superior e distinguido pudesse influir positivamente nos destinos sociais. ${ }^{32}$

Esta disposição para a polêmica foi alvo de diversas críticas, principalmente após a publicação do trabalho sobre Machado de Assis. Mas talvez a crítica de José Veríssimo seja a mais exemplar a respeito dos significados dessa postura em meio à sociedade da época. O momento de sua publicação foi logo após o discurso de recepção proferido por Sílvio Romero para o ingresso de Euclides da Cunha na Academia Brasileira, em que Sílvio tece fortes críticas ao governo diante de algumas autoridades convidadas, transformando um discurso literário em uma afronta a quase todos os presentes. Após esse discurso, todos os textos da recepção a novos acadêmicos passaram a ser obrigatoriamente censurados. José Veríssimo, um dos intelectuais influenciados pela Escola de Recife e que reviu na maturidade sua perspectiva teórica, faz a reprimenda a essa descompostura de Sílvio Romero ao afirmar que o discurso acadêmico pode

[...] exprimir, e feito por tais homens tem exprimido, os mais alevantados, os mais livres, os mais novos pensamentos. Tem, porém, a sua maneira, se quiserem, a sua retórica própria, que é aliás apenas a de um salão de boa companhia. Neste todas as opiniões e ideias podem ser aventadas e sustentadas, contanto que não ofendam susceptibilidades respeitáveis ou veneráveis delicadezas de sentimento, e a linguagem e os gestos se acomodem ao ambiente

\footnotetext{
${ }^{31}$ ROMERO. Cantos do fim do século, p. 236. Grifo meu.

${ }^{32}$ Em carta a Artur Guimarães, de início de 1898, Sílvio justifica esta retórica agressiva de seu livro sobre Machado de Assis e sua posição frente a Tobias Barreto, afirmando que o defendeu "[...] primeiro, pelo seu mérito intrínseco; segundo, para justificar o meu próprio critério; terceiro, como meio de guerra. É uma clava que costumo brandir contra certos semideuses cá da terra". Apud MAGALHÃES JUNIOR, Vida e obras de Machado de Assis, p. 82.
} 
social. A própria existência de qualquer sociedade policiada supõe o sacrifício das expansões demasiado pessoais, em proveito das vantagens que tira o homem da sociabilidade. Sob este aspecto só é verdadeiramente livre o selvagem ou o grosseirão. A prolixidade somente já é num salão ou numa Academia um documento de mau gosto e de má-criação. ${ }^{33}$

Assim, a "forma de vida" que parece inspirar Sílvio Romero se consolida nessa oposição entre, de um lado, a sua concepção de autenticidade do brasileiro somada à postura combativa que espera do homem de letras e, de outro lado, a sociedade, com seus cerimoniais. Para ele, tais cerimoniais e excessos de formalismo seriam empecilhos ao desenvolvimento da raça brasileira mestiça e, também, ao intelectual como centro de forças. Dessa forma, a crítica de José Veríssimo revela o sentido atribuído à ideia de sociedade em sua época, em que o comportamento individual adequado baseia-se na contenção dos impulsos, em proveito de certo senso de igualdade no "salão". Justamente o contrário do que defendia Sílvio, tanto para definir o brasileiro como para qualificar a postura combativa do intelectual. O seu senso de liberdade, amparado nesse caráter expansivo, se choca com a sensibilidade da conveniência e justifica, para ele, seu tratamento descortês ao presidente da Academia Brasileira, ao designá-lo por "mestiço", "pacato", "burguês prazenteiro", de personalidade indecisa, entre outras menções já registradas ao longo do artigo. Pois, para Sílvio, a sociedade não é um "convento de monjas", é a incessante luta através da qual aquele que porta os valores mais elevados de afirmação da raça deve, portanto, enfrentar qualquer conveniência que o impeça.

Machado de Assis, nesse sentido, representa para o crítico um modelo inadequado ao processo de miscigenação, e a contestação pública de seu estilo literário, de sua capacidade intelectual e de sua defesa ao "tédio à controvérsia", permitiria a Sílvio dar relevo ao próprio modelo intelectual que acredita ser mais útil e apropriado ao Brasil. Ao contrário da serenidade de Machado, o verdadeiro artista agiria por impulso, na convicção de que obedecer à própria natureza permitiria a emergência de uma potência interna. Deste modo, a defesa cética de uma ironia compassiva diante as veleidades sociais, tão característica do pessimismo machadiano, inclusive como forma de crítica à ambição do conhecimento científico em se constituir como o principal parâmetro de intervenção pública, é uma postura diante da vida que apenas soaria a

\footnotetext{
${ }^{33}$ VERÍSSIMO, José Veríssimo: teoria, crítica e história literária, p. 141-142.
} 
Sílvio como fragilidade e insegurança. A maior motivação intelectual de Sílvio Romero parece ser a criação da memória nacional a partir de parâmetros objetivos, portanto, acima das conveniências sociais que pudessem limitar ou conter seus pretendidos avanços.

A forma como Sílvio alia objetividade e luta nos permite caracterizar seu comportamento e visão de mundo a partir da noção de conquista, devido à sua pretensão em "colonizar" a sociedade, torná-la, em certa medida, a reprodução de sua imagem. Essa correlação entre arte/conhecimento e sociedade se choca obrigatoriamente com a ideia de sociabilidade sugerida por José Veríssimo. E esse contraste é bastante exemplar para caracterizar o espírito de aventura e conquista expresso na retórica de embate empregada por Sílvio Romero.

Se partirmos do pressuposto defendido por José Veríssimo, a liberdade individual não pode ser confundida com expansão desenfreada dos próprios impulsos, sob o risco de converter liberdade em selvageria. Segundo o trecho citado, a única liberdade possível é aquela permitida pela maneira do salão de boa companhia, cuja expansão é limitada pelo tato, uma noção cara às formas sociais do século XIX. Assim, a atitude assumida por Sílvio Romero, independente e propositalmente desrespeitosa das conveniências, nos conduz à imagem do aventureiro, ${ }^{34}$ que parte dos próprios critérios para definir os vínculos que estabelece com o mundo social, à revelia, portanto, de parâmetros de conduta "sociáveis" ou ainda de formas retóricas mais prudentes.

Apesar de seu compromisso com a conquista, em imputar seus princípios como modelo de conduta, os meios escolhidos - principalmente a polêmica - são marcados pelo risco, ao qual não há certeza de sucesso. E talvez a maior prova desse risco de insucesso seja justamente sua obra sobre Machado de Assis, em que o aumento da temperatura crítica, o ímpeto de luta e aplicação inadvertida de um modelo teórico rígido, provocou algumas manifestações públicas de repúdio. ${ }^{35}$ Assim, a polêmica, que é a retórica usual da expressão intelectual de Sílvio Romero, revela essa ausência de

\footnotetext{
${ }^{34}$ SIMMEL, The Adventure, p. 187-188.

35 O mais famoso desses repúdios é, sem dúvida, o de Lafayette Rodrigues Pereira, que, sob o pseudônimo de Labieno, aproveita a ocasião para uma desforra com Sílvio Romero. Julga-o não apenas pelo livro sobre Machado de Assis, mas por algumas das suas bases filosóficas e estéticas. PEREIRA, Vindiciae. No entanto, outros mais próximos a Machado também escreveram publicamente contra o livro de Sílvio Romero, como Magalhães de Azeredo em 1898, sob o título Estudos Contemporâneos Machado de Assis e Sílvio Romero, publicado no Jornal do Comércio de 9 de maio. MAGALHÃES JUNIOR, cit.,p. 84.
} 
correlação prudente entre o passado e o futuro ao apostar em transformações abruptas do cenário literário. Na luta há ganhadores e perdedores, e por mais que a força penda para um dos lados, o risco implícito sempre produz seus revezes. Com o livro sobre Machado de Assis, Sílvio Romero fez uma aposta arriscada e marcou seu nome como aquele responsável, provavelmente, pela crítica literária mais equivocada de nossa história, pelo menos no tocante ao lugar que acreditava ser o de Machado de Assis na tradição literária brasileira.

Referências:

AGUIAR, Maurício Maia. Retratos de Machado de Assis: sabedoria, genialidade e melancolia na crítica literária fin de siècle. Rio de Janeiro: IESP-UERJ, 2012. Tese (Doutorado em Sociologia) - Programa de Pós-Graduação em Sociologia, Universidade do Rio de Janeiro, Rio de Janeiro, 2012. Disponível em: $<$ http://www.bdtd.uerj.br/tde_arquivos/53/TDE-2013-03-01T100934Z2937/Publico/tesemauricio.pdf $>$. Acesso em: 15 dez. 2013.

ARAÚJO, Ricardo Benzaquen de. "Deuses em miniatura: Notas sobre genialidade e melancolia em Gilberto Freyre". Travessias, $n^{\circ} 1$. Rio de Janeiro: Editora Travessias, 1999.

BARBOSA, João Alexandre. A tradição do Impasse: linguagem da crítica e crítica da linguagem em José Veríssimo. São Paulo: Editora Ática, 1974.

CANDIDO, Antonio. O método crítico de Sílvio Romero. São Paulo: EDUSP, 1988.

FREYRE, Gilberto. Sobrados e mucambos: decadência do patriciado rural e desenvolvimento do urbano. São Paulo: Global, 2003.

GUIMARÃES, Hélio de Seixas. Os leitores de Machado de Assis: o romance machadiano e o público de literatura no século 19. São Paulo: EDUSP: Nankin Editorial, 2004.

LUKÁCS, Georg. On the nature and form of the essay. In: . Soul and Form. Massachusetts: The Mit Press: Cambridge, 1980.

MAGALHÃES JUNIOR, Raimundo. Vida e obra de Machado de Assis. Volume 4, Apogeu. Brasília: Civilização Brasileira, 1981. 
MAYA, Alcides. Machado de Assis: algumas notas sobre o humour. Porto Alegre: Editora UFSM, 2007.

PEREIRA, Lafayette Rodrigues. Vindiciae. Rio de Janeiro: José Olympio Editora, 1940.

RABELLO, Sylvio. Itinerário de Sylvio Romero. Rio de Janeiro: Livraria José Olympio Editora, 1944.

ROMERO, Sílvio. Cantos do fim do século. Rio de Janeiro: Typografia Fluminense, 1878.

ROMERO, Sílvio. Machado de Assis: Estudo comparativo de literatura brasileira. Campinas: Editora UNICAMP, 1992. Livro publicado originalmente em 1897.

ROMERO, Sílvio. Poesia - segunda fase do romantismo. In: . Teoria, crítica e história literária. São Paulo: EDUSP, 1978.

SIMMEL, Georg. Schopenhauer e Nietzsche. Trad.: César Benjamin. Rio de Janeiro: Contraponto, 2011.

SIMMEL, Georg. The Adventure. In: Chicago: The University of Chicago Press, 1971. . On individuality and social forms.

TAINE, Hippolyte. Da natureza e produção da obra de arte. Trad.: Paulo Braga. Lisboa: Editorial Inquérito, 1940.

VERÍSSIMO, José. A literatura brazileira: Sua formação e destino. In: Estudos Brazileiros: 1877-1885. Pará: Livraria Universal, 1889.

VERÍSSIMO, José. José Veríssimo: Teoria, crítica e história literária. São Paulo: EDUSP, 1977.

WEBER, Max. A ciência como vocação. In: Ciência e Politica: duas vocações. São Paulo: Editora Cultrix, 2002.

A objetividade do conhecimento na ciência social e na ciência política. In: Metodologia das ciências sociais. Campinas: Editora Cortez, 1992.

Maurício Maia Aguiar é professor de sociologia do departamento de Ciências Sociais da UFCG e doutor, também em sociologia, pelo IESP-UERJ com tese que analisa e acompanha a recepção crítica de Machado de Assis logo após a publicação de seus romances, poesias e contos. Possui formação voltada para o Pensamento Social Brasileiro e Sociologia da Cultura, com interesse preferencial pelas sociabilidades artísticas e intelectuais brasileiras do final do século XIX. E-mail: <aguiar.mauricio.m@gmail.com>

Recebido: 17.01.2014

Aprovado: 11.04.2014 